\title{
Sustainable Transportation System
}

\author{
Raxshitha Sasikala
}

\begin{abstract}
Developing cities and its opportunities have become a global attraction, inviting the rural population into urban area. This rate of increase in population and overbuilt roadways have outgrown the possibility of shaping our city and making it accessible for all. It is important to note that connecting various parts of the city, giving life to the streets are vital for the livelihood of any city. Energy efficient modes of transportation, combining trips or travelling less by adapting transit oriented development can enhance the environmental quality and quality of life. Therefore it is important to understand the benefit of sustainable transportation system and its role in developing a sustainable environment
\end{abstract}

Keywords: Developing city, Sustainable transportation, energy efficient, quality of life, sustainable environment

\section{INTRODUCTION}

$\mathrm{O}$ verpopulation, traffic congestion, excessive consumption, pollution, and depletion of resources have created a major challenge in developing cities. According to the 2011 census of India, it is seen that the level of urbanization has increased from $27.81 \%$ in 2001 to $31.16 \%$ in 2011 . Thus the importance of developing sustainable cities is through sustainable transportation systems. This issue has also been addressed by the United Nations Development Program in 2015[1], under the seventeen sustainable development goals

In the present scenario it has been noted that planning even the simplest transportation system such as pedestrian pathway or a bicycle lane has become challenging due to the haphazard development of the city. There are several factors that contribute to the need of sustainable transportation; such as; traffic congestion, reduced air quality, lack of connectivity and safe access. According to the study conducted by the World Bank on Urban air pollution, Transport is universally considered by far the most important cause of air pollution.

\section{DEFINING SUSTAINABLE DEVELOPMENT}

Sustainability has been addressed in several platforms that has helped understand the meaning and what it represents. A development that can provide for the present with the available resources that can be regenerated for future generations to come. [2]. In today's world, sustainability not only defines the need of the future but also the need to develop sustainable method that is necessary for the survival of the human race and the planet.

Revised Manuscript Received on December 09, 2019.

* Correspondence Author

Raxshitha Sasikala*, Research Scholar, Kalasalingam School of Architecture, Kalasalingam Academy for Research and Education, Tamil Nadu, India. Email: raxshi91@gmail.com

Dr. (Prof) N.Lakshmi Thilagam, Director \& Professor, Kalasalingam School of Architecture, Kalasalingam Academy for Research and Education, Tamil Nadu, India. Email: hodbarch@klu.ac.in
Based on the three pillars of sustainability: economy, environment and society, addressed in the Brundland Commission Report [2], Sustainable development often is illustrated as a combination of sustainable environment, sustainable economy and sustainable society

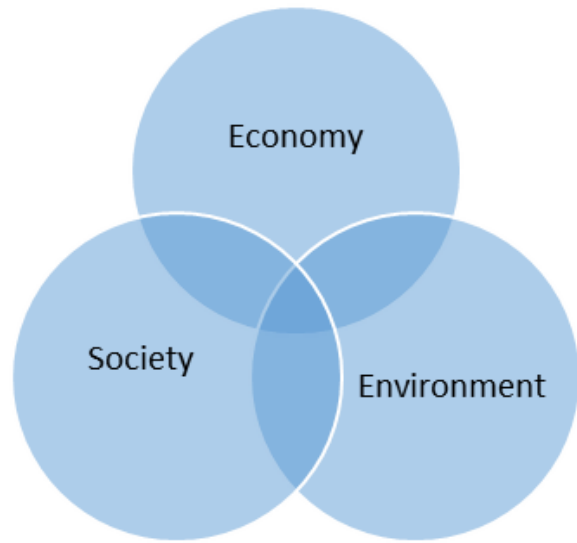

Fig. 1. Three pillars of sustainable development

There are different ways of conceptualizing sustainable development. Our understanding of the concept tends to change with the development in technology and arousal of new impacts.

At first instance, sustainability tends to be addressed as a single entity because it majorly covers developmental issues related to socio economic conditions. However this being valid, it is important to foresee that sustainability has to be studied with respect to several aspects such as transportation, availability of resources, and growth of population, pattern of consumption, governance and climate change adaptation.

\section{SUSTAINABLE TRANSPORTATION SYSTEM}

The definition of Sustainable Transportation given by the Organisation for Economic Co-operation and Development in terms of environment is "Transportation that will not endanger the health of the people or ecosystems and at the same time, it can meet the needs for access considering (a) use of renewable resources at below their rates of regeneration, (b) use of nonrenewable resources at below the rates of development of renewable substitutes. [3]. Sustainable transportation is any means of transportation that has low impact on the environment and does not consume resources than that is available. Transportation system that uses renewable resources without exceeding regeneration rate and the transportation system that uses non-renewable resources without exceeding the rate of development of sustainable resources is considered as sustainable transportation system. [4] 


\section{TRANSPORTATION IMPACT ON SUSTAINABILITY}

The impact of transportation can be categorized according to the three pillars of sustainability: Economy, Environmental and Social. [5]

\section{A. Economic factor:}

Any transportation indicator or factor that affects the economy is addressed here. Such as, damages caused by traffic, cost incurred by accident, requirement for additional resources and requirement for advancement in facility

\section{B. Environmental factor}

Any transportation indicator or factor that affects the environment is categorized here. Such as, reduced quality of air and water due to pollution, noise pollution due to traffic congestion and depletion of resources

\section{Social factor}

Any transportation indicator or factor that affects the society is categorized here. Such as, impact on human health, reduced quality of livability and loss of connectivity

These factor overlap while creating an impact on sustainable development and hence it has to be addressed as a whole. This implies that sustainability planning does not always require tradeoffs between economic, social and environmental objectives, but rather a matter of finding strategies that help achieve all of these objectives over the long term by increasing transportation system efficiency. [5] "The goal of sustainable transportation is to ensure that the effect on environment, social and economic are considered for any transportation activity.'[6]

\section{V.PRINCIPLES OF SUSTAINABLE TRANSPORTATION SYSTEM}

The eight principles discussed here were addressed at the OECD International Conference, Vancouver Canada, and 24-27 March 1996

\section{A. Access}

The transportation system, although provided for a community, should be made accessible at the at all times for a person to get connected to another person, place, goods or services. Accessibility should aim at micro level integration of services.

\section{B. Equity}

It is important to note that the basic transportation network should be well integrated despite social or inter regional differences. Such system should be inclusive of women, the poor, disabled and the rural population

\section{Health and Safety}

Sustainable transportation system should enhance the quality of life by being designed to operate in a way that provides safety and protects the social; wellbeing of the people. The designed operating system should be able to minimalize the cause and impact of accidents, protecting physical and mental health of the users.

\section{Individual Responsibility}

People have started to choose private transportation over public as the cost of investments and maintenance have become affordable and reachable to all. Also providing people with more independent and secure way to commute [7] it is the responsibility of an individual to look into considering or opting a sustainable transportation network. The responsibility of an individual towards natural environment has to be addressed in terms of consumption and movement

\section{E. Integrated Planning}

It is the responsibility of the stakeholders involved in the transportation planning to ensure the integrated approach and the sustainable functioning of the system

\section{F. Pollution Prevention}

It has been noted that that $32-41 \%$ of $\mathrm{CO} 2$ emissions have resulted as the action of individuals opting for private transportation system. [8]. Public transportation must be made available and promoted in order to reduce the emissions that can be life threatening to the public, the climate and ecological balance.

\section{G. Land and Resource Use}

Transportation system should be designed making use of available land efficiently by considering these factors: land form, land availability, prevailing habitation and biodiversity

\section{CHALLENGES TO BE ADDRESSED IN SUSTAINABLE TRANSPORTATION SYSTEM}

\section{A. Setting up an integrated framework}

An integrated framework can be set up at two levels: (i) Interlinkage of several factors (society, economy and environment) ii) Micro level connectivity (the pedestrian connectivity between metro station and bus station.)

\section{B. Growing demand, limited resources}

The issue of availability of resources and growing demand has been addressed at several global conferences. The goal set for sustenance has to be prioritised with a set of alternative options of improved transportation system.[9]

\section{Affordability}

Often the development of any new system can be questioned with its affordability. The promotion of public transportation system should address the affordability of people of all classes: the rural, urban and immigrants. People opt for private transport over public transport due to affordability (for example. In certain Indian cities carpooling system has become more affordable compares to the metro tickets sold) this is opted during led traffic hours and debatable for different locations [9] 


\section{Involvement of governance}

The government can create a platform to reach people and addressed the importance of adapting a sustainable transportation system. [10]

\section{E. Change in the thought process of every individual}

Public must be made aware of their role in developing a sustainable society. A private transport mode, although being made affordable, it should be in the interest of an individual to reconsider the thought of adapting with regards to it effects and causes to the environment. People should be educated with the rising demand for a sustainable development

\section{POLICY FRAMEWORK}

It is to be noted that the development of any transportation network should consider the need of the public in the future and not just limiting to the present. Although the framework provides basic transportation system, it has been noted that people do not opt for such networking system as it does not offer safety, security and accessibility measures. [11] Policymakers must rethink the provision of sustainability while targeting a larger population and the increased growth rate in consumption

It is in the capacity of the transportation planners and policymakers to address the challenges to make a major impact in people's perspective of a sustainable transportation system. This can contribute to improving the quality of life of people in rural and urban areas. This can also result in benefiting the economic growth and maintaining the environment in a sustainable way.

\section{CONCLUSION}

A sustainable development can only prevail taking into account all the factors that contributes to the existence of a society. While defining sustainable transportation, it is understood that any transportation depending on non-renewable resource without affecting its regeneration and the transportation that relay on renewable resource without depleting it for future generation is considered as sustainable transportation. For any society to develop with sustainability it is important that people change their perspective of consumption. Increasing or betterment of infrastructure may not be the solution reducing traffic as it mostly result in increased use of private vehicles. Any well integrated inclusive system that is accessible and user friendly can result in a sustainable transportation system.

\section{REFERENCE}

[1] The Sustainable Development Goals Report, United Nations Development Programme, 2015

[2] Brundland Commission Report, "Our Common Future" 1987

[3] OECD Proceedings, Towards Sustainable Transportation, The Vancouver Conference, 24-27 March, 1996

[4] Daly, H.E., 1991. Ecological economics and sustainable development: from concept to policy (No. 1991). World Bank, Environment Department, Policy and Research Division

[5] Litman, Todd and David Burwell (2006), "Issues in Sustainable Transportation," International Journal of Global Environmental Issues, Vol. 6, No. 4

[6] Moving on Sustainable Transportation (MOST) (1999) Transport Canada
[7] Camagni, R., Gibelli, M.C., Rigamonti, P., 2002. Urban mobility and urban form: the social and environmental costs of different patterns of urban expansion. Ecol. Econ. 40 (2)

[8] Jack N. Barkenbus, Eco-driving: An overlooked climate change initiative, Energy Policy 38 (2010) 762-769

[9] Sudhakar Yedla, Ram M. Shrestha, Multi-criteria approach for the selection of alterna tive options for environmentally sustainable transport system in Delhi

[10] Christy Mihyeon Jeon and Adjo Amekudzi, Addressing Sustainability in Transportation Systems: Definitions, Indicators, and Metrics

[11] Julian Smith, Edward Clayton, Daniel Hanson, Building sustainable, inclusive transportation systems: A framework for the future, 2017

\section{AUTHORS PROFILE}

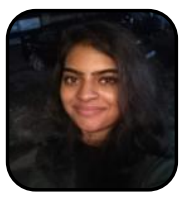

Ar. Raxshitha Sasikala pursuing Ph.D. in Architecture from school of Architecture, Kalasalingam Academy for Research and Education, TamilNadu, India. She has acquired her B.Arch. Degree from Thiagarajar College of Engineer, Madurai, Tamilnadu and M.Arch Degree from RV College of Architecture, Bangalore, Karnataka. She is a registered Architect with Council of Architecture, India and a member of the Indian Institute of Architects.

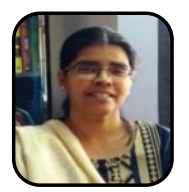

Dr. N. Lakshmi Thilagam is an Architect and Urban Designer and holds a $\mathrm{PhD}$ from the Indian Institute of Technology, Kharagpur, India. Her research interests are traditional urbanism, space syntax application for historic cities, heritage and urban conservation. She is currently conducting research to analyze the principles of sustainability exhibited in the traditional urban patterns of the historic cities of Tamil Nadu. As a passionate academician who has been teaching for the last 2 decades she also writes on the subject of Architectural education. 